\title{
A review of social participation interventions for people with mental health problems
}

\author{
Martin Webber $^{1} \cdot$ Meredith Fendt-Newlin $^{1}$
}

Received: 17 November 2016 / Accepted: 26 February 2017 / Published online: 12 March 2017

(C) The Author(s) 2017. This article is published with open access at Springerlink.com

\begin{abstract}
Purpose The association between social networks and improved mental and physical health is well documented in the literature, but mental health services rarely routinely intervene to improve an individual's social network. This review summarises social participation intervention models to illustrate different approaches which practitioners use, highlight gaps in the evidence base and suggest future directions for research.

Methods A systematic search of electronic databases was conducted, and social participation interventions were grouped into six categories using a modified narrative synthesis approach.

Results Nineteen interventions from 14 countries were identified, six of which were evaluated using a randomised controlled trial. They were grouped together as: individual social skills training; group skills training; supported community engagement; group-based community activities; employment interventions; and peer support interventions. Social network gains appear strongest for supported community engagement interventions, but overall, evidence was limited.

Conclusions The small number of heterogeneous studies included in this review, which were not quality appraised, tentatively suggests that social participation interventions may increase individuals' social networks. Future research needs to use experimental designs with sufficient samples and follow-up periods longer than 12 months to enable us
\end{abstract}

Martin Webber

martin.webber@york.ac.uk

1 International Centre for Mental Health Social Research, Department of Social Policy and Social Work, University of York, Heslington, York YO10 5DD, UK to make firm recommendations for mental health policy or practice.

Keywords Social networks · Social isolation · Interpersonal relationships · Psychosocial intervention · Review

\section{Introduction}

The social environment-and, in particular, close relationships (either intimate or platonic where a person feels close to another)_-plays a key role in physical and mental health, including depression [1, 2] and psychoses [3]. Being socially connected is not only important for psychological and emotional well-being, but it also has a positive impact on physical well-being [2] and overall longevity [4]. Loneliness, social isolation and living alone are all risk factors for coronary heart disease and stroke [5], and a leading cause of mortality [6].

People with psychosis have fewer social relationships beyond their families than those without [3, 7]. Reasons for this are related both to negative symptoms of the disorder: anhedonia, emotional dullness and low energy, which impairs the motivation and ability to establish and maintain social relationships [8]; low confidence and poor selfesteem [9, 10]; as well as marked social disadvantages such as unemployment [10] and a higher likelihood of living alone [11] with fewer opportunities to utilise social skills. It is unclear whether these are a consequence of the illness or whether they predate it [12]. However, social disadvantage contributes to an increased risk of psychoses [13]. Similarly, for example, people with depression interact with their social environments in ways which define, and 
are defined by, their mental health; social isolation is both a cause and consequence of depression $[14,15]$.

The size of social networks can be used as a measure of isolation or connectedness. Social networks include close, supportive relationships with family and friends, as well as more casual interactions with wider contacts in the community. Smaller social networks are associated with increased hospital admissions [16], increased symptomology and poorer social functioning [17] for people with a diagnosis of schizophrenia. Mediators of social networks include better overall health, a greater sense of independence and fewer social stressors. These mediators have been shown to have various positive effects on: increasing feelings of belonging and reducing psychological distress [18]; instilling feelings of trust and reciprocity [19]; increasing engagement with mental health services [20]; enhancing community participation and improving quality of life [21].

There is increasing evidence to suggest that rather than simply building social contacts and relationships within a network, it is important for interventions to emphasise the quality of relationships and having meaningful social roles outside the formal mental health system [22]. Individuals need to receive the benefits of social interaction, and to believe that their contribution to the relationship is valued [23].

Despite the evidence linking social networks to improved mental and physical health, there remains a gap in mental health service provision between providing treatment and effectively addressing psychosocial well-being. Systematic reviews $[8,24]$ have identified that one potential way of addressing this gap is by utilising social interventions which link people beyond mental health services to community-based sources of support. Social interventions aim to balance service users' needs, assets and the ability of mental health services to deliver appropriate, holistic support by engaging with the voluntary and community sector, where many services such as interest-based classes and support groups are provided. Accessing a broad range of community-based services is increasingly identified as having the potential to address the limited 'one-size-fits-all' approach to managing long-term conditions [25].

Interventions focusing on social participation-having an active role in one's community or society and engaging with a wider range of people to enhance the diversity of one's network-require making social connections with people beyond health and social care services. Diverse social connections enhance the resourcefulness of an individual's network, reduce isolation and support recovery from mental health problems [26, 27]. However, there is a paucity of evidence on social participation interventions, possibly because of the complexity of developing and evaluating them. A systematic review of trials of interventions to enhance the social networks of people with psychosis found only five trials [8], and a broader review of social participation intervention evaluations for people with mental health problems found only 14 intervention studies [24]. Many of the studies included in these reviews were susceptible to bias.

This review aims to summarise social participation intervention models which have at least some evidence of positive social network outcomes. Its purpose is to illustrate the diversity of approaches which practitioners use, highlight gaps in the evidence base and suggest future directions for research.

\section{Methods}

This review drew upon and updated our earlier systematic review on social participation interventions [24]. The population was people with any diagnosed mental health problem, though those with a primary diagnosis of substance misuse were excluded. Only psychosocial interventions were included in the review. A psychosocial intervention was defined as one with a specific social component which addresses psychological and social needs rather than biological ones. The intervention was either with individuals or groups. Pharmacological, physical or psychological interventions with no social components were excluded. Also, online interventions which did not involve any faceto-face contact were excluded. Studies with or without a comparison intervention were considered for inclusion in the review. Outcomes of interest were social networks or social participation where they were measured as primary or secondary outcomes and attributable to the intervention. Group interventions which measured social functioning and relationships within groups were included, as groups can be viewed as a microcosm of wider social networks. However, studies using participants' subjective appraisal or satisfaction with networks as outcomes were excluded. Due to resource constraints we excluded those not written in English.

A systematic, electronic search was conducted on the databases PsycINFO, MEDLINE, Pubmed, CINAHL, Embase, Social Policy and Practice, Social Services Abstracts, and the Cochrane Library. Reference lists of studies meeting our inclusion criteria were searched to identify further papers for inclusion in the review. The search was completed in November 2016. A hand search for papers to include in the review was carried out in journals such as Journal of Mental Health, Social Work Research, and Journal of Social Work, which have recently published papers in this field. The combination of terms was deliberately broad to increase sensitivity of the search and identify all eligible interventions or models of practice. 
The search strategy was defined using Medical Subject Headings (MeSH) terms or equivalent adaptations to reflect different indexing, search functions and syntax available. The search strategy used adjectives or derivatives of 'mental disorders', 'social networks' and 'intervention' that were combined using a series of Boolean 'AND/OR' operators in Title, Abstract, Keyword and Indexing Terms. A sample search strategy is:

(social* OR communit*) adj1 (inclus* OR capital OR engag* OR participat* OR network* OR support or enterpri* OR connect*) AND (psych* OR mental/exp) AND (intervene* OR training* OR program* or trial OR stud* OR rct OR eval*).

Interventions were grouped into six categories (individual social skills training; group skills training; supported community engagement; group-based community activities; employment interventions; peer support interventions) using a modified narrative synthesis approach [28]. This involved the comparison of intervention characteristics to identify common and distinctive elements. Similar interventions were grouped together, and divergent ones were categorised separately.

\section{Results}

Nineteen interventions with evidence of improved social network or participation outcomes were found, six of which were evaluated using a randomised controlled trial. A total of 14 countries were involved in the evaluations of the interventions included in the review. These are described in Table 1 and discussed below in six broad groups: individual social skills training; group skills training; supported community engagement; group-based community activities; employment interventions; and peer support interventions. Other studies are referred to in the narrative synthesis to locate the interventions in the wider context.

\section{Individual social skills training}

Mental health problems and social skills difficulties often coexist [29]. Social skills training is provided as a way to improve individuals' ability to manage social relationships, and evidence suggests that it is effective in improving social functioning and social relations, particularly when conducted in community settings [30]. However, it is no longer recommended by the National Institute for Health and Care Excellence in the UK for people with a diagnosis of schizophrenia [31], possibly because the evidence has been rated as very low quality and may not be generalisable, as shown in a recent Cochrane Review which reported most studies were conducted in China [32].
An evaluation of an intervention model developed and piloted in the Netherlands (Interpersonal Community Psychiatric Treatment (ICPT) [33]) found that individual social skills training increased participants' social network size and their care utilisation decreased [34]. However, the structured nature of the skills training did not appear to suit everyone. The intervention was more successful when based on participants' goals rather than workers' preferences, which enabled them to be more engaged in decisions involving their own care and motivated towards recovery [35].

\section{Group skills training}

Group skills training for people with severe mental health problems is a common approach to addressing social deficits or training people to undertake specific roles. For example, a six-month training programme for peer advocates, PEARL, improved individuals' relationships with others [36]. An uncontrolled cohort study of a residential community reintegration programme for adults with severe chronic brain injury and depression also reported overall improvement in emotional well-being, quality of life, level of community integration and employability one year after group skills training [37]. This study found greater improvement in social outcomes when participants were able to generalise skills to their own daily life situations.

Groups for Health is a non-diagnosis specific manualised intervention delivered in five sessions, which aims to increase connectedness by building group-based social identifications [38]. The intervention draws upon social identity theory [39] and self-categorisation theory [40] through its understanding that group membership provides people with a distinctive sense of self. In particular, it was informed by the social identity model of identity change [41] which emphasises group processes which target social connectedness. A pilot study found reductions in loneliness and improved social functioning for the young people with depression and anxiety who participated in it [38], though there is no evidence yet of its impact on wider social networks.

Social Cognition and Interaction Training (SCIT) is a group-based programme for people with a diagnosis of schizophrenia [42]. Influenced by the fields of social psychology, acceptance-based psychotherapies and social neuroscience, it addresses deficits and biases in social cognitions. It has a growing evidence base of its effectiveness [42], though its 20-session programme has been condensed by some researchers to reduce participant burden and increase retention [43, 44]. Several trials have found positive effects of SCIT on social functioning [45-47], though social network outcomes are yet to be measured. 


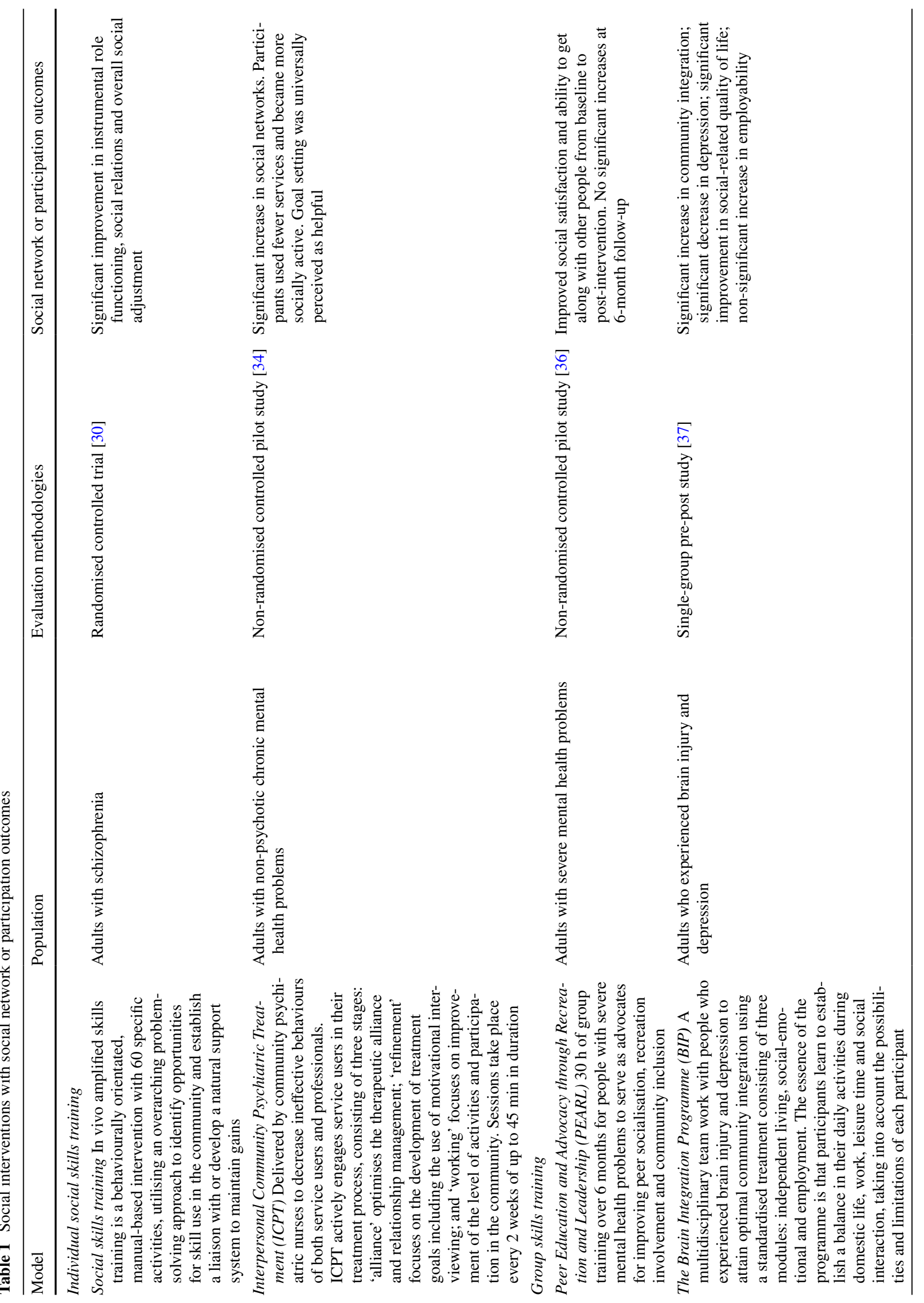




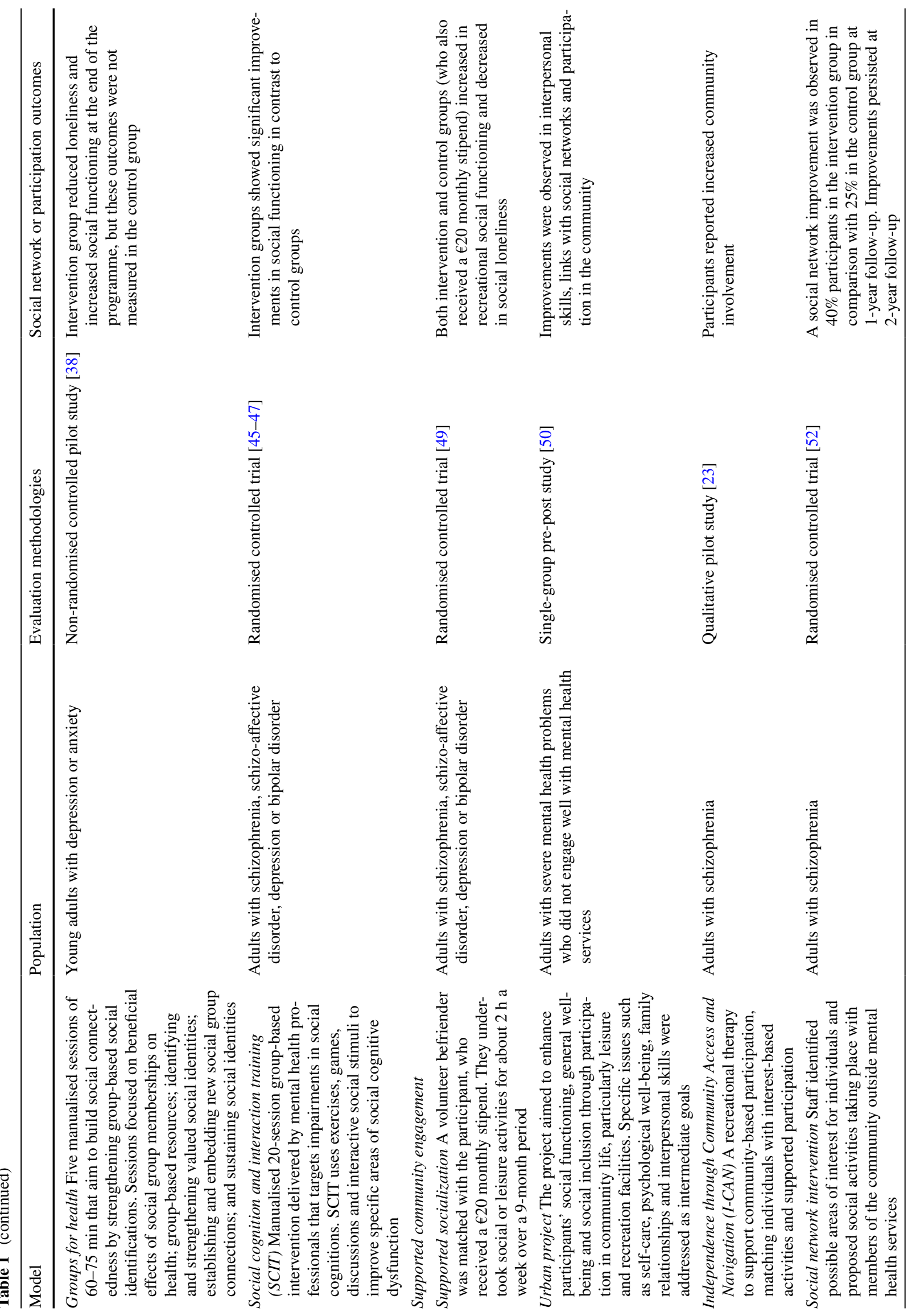




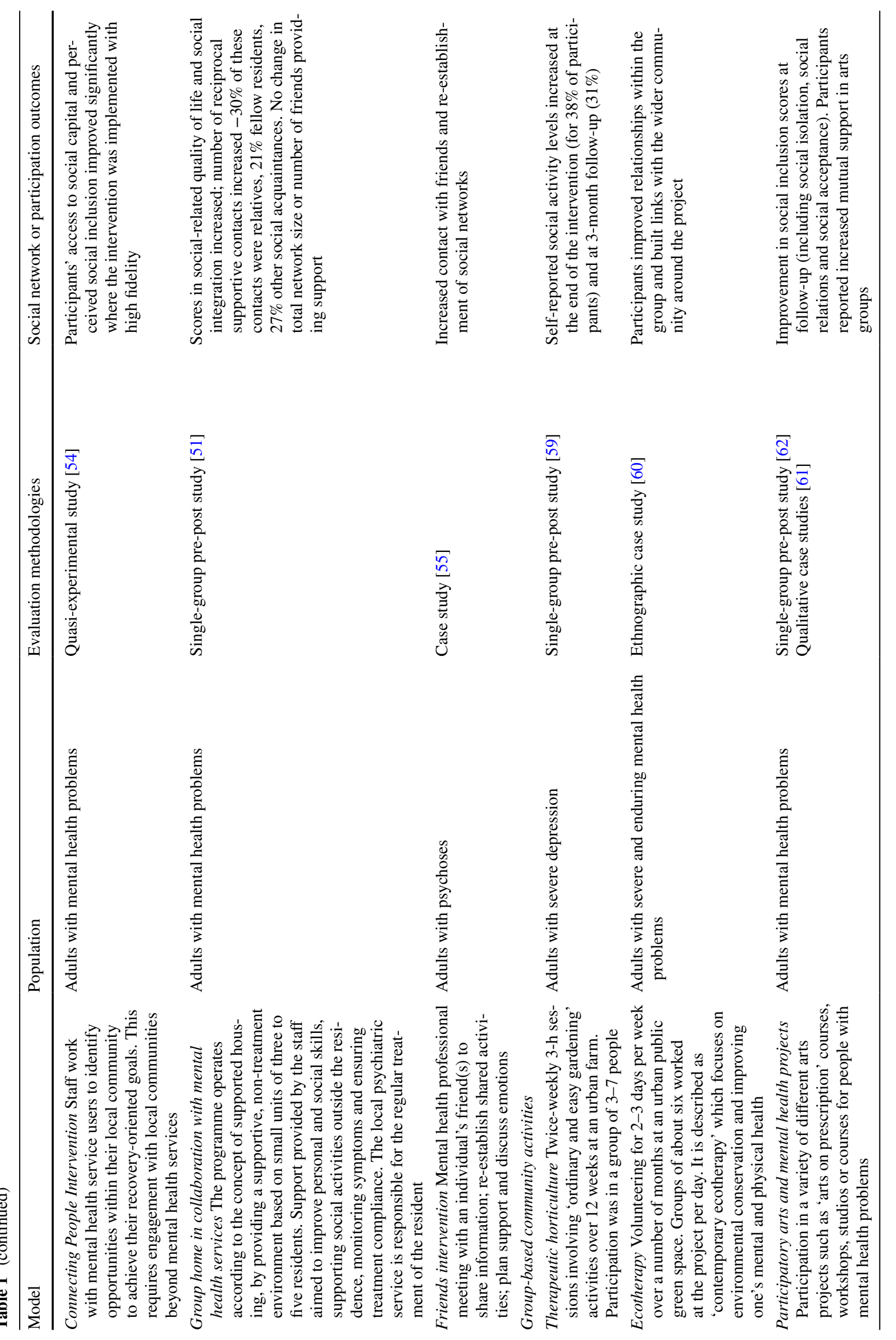




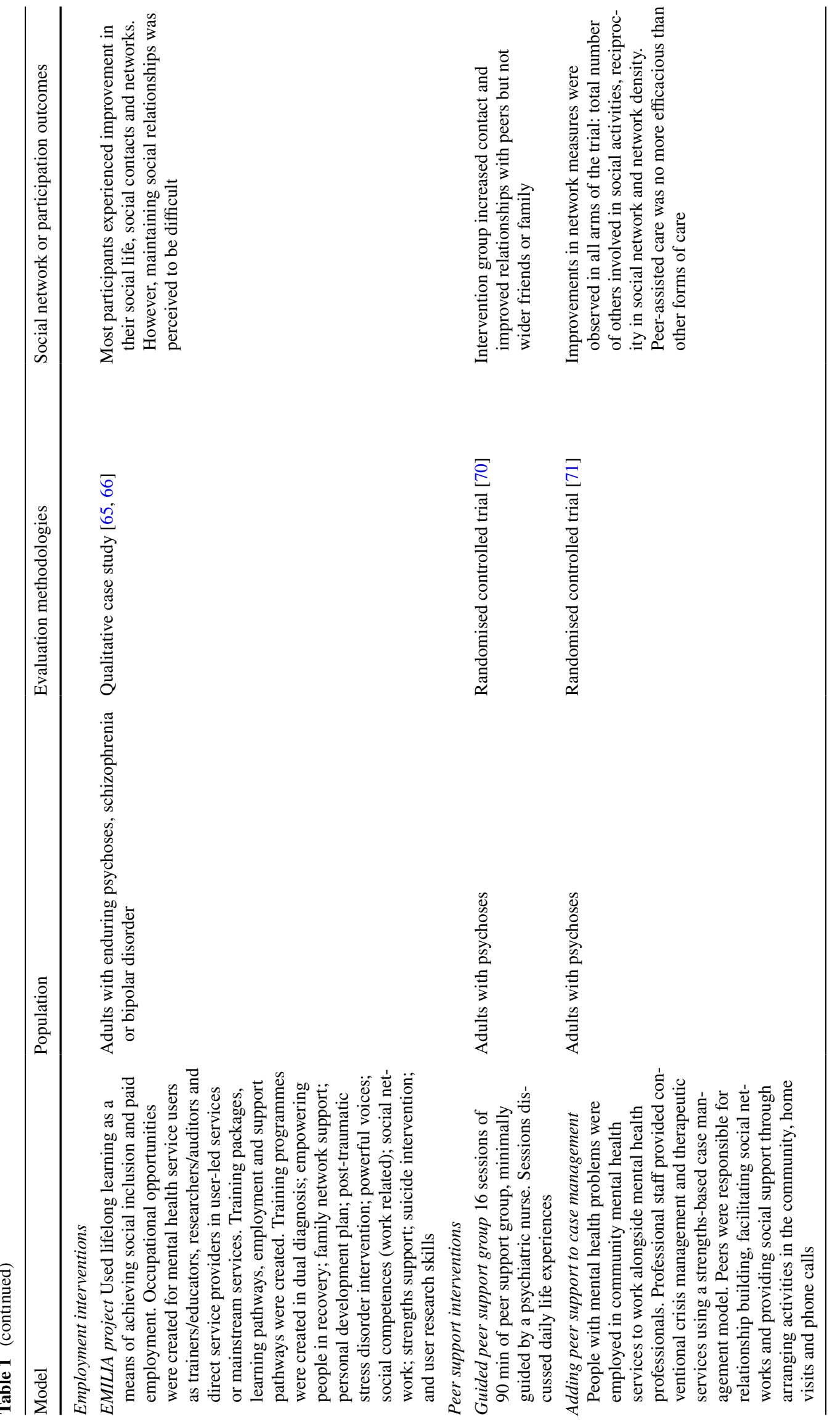




\section{Supported community engagement}

Volunteer befriending for people with depression has been found to be effective in reducing symptoms [48]. Therefore, the matching of a volunteer befriender with a person with mental health problems, and providing them with a modest budget for social and leisure activities, could assist them to socialise more and enhance their social networks. However, a trial of this in Ireland found no difference in social functioning and loneliness between intervention and control groups [49].

In contrast, a project in Italy involving a team of professionals working flexibly to meet the needs of people who were difficult to engage with mental health services appeared more successful at engaging them in community leisure and recreation facilities [50]. This was associated with significant improvements in social functioning. Additionally, a small pilot study of a recreational therapy intervention similarly found increased community engagement of its participants [23], and an evaluation of small group homes found increased social integration [51].

Perhaps the strongest evidence that supported community engagement is effective can be found in a trial of a social intervention in Italy whereby people with schizophrenia were supported to engage in social activities in their communities [52]. This resulted in significant social network improvements which were sustained after two years. Similarly, in the UK an intervention model which engages people in activities, organisations and groups in their local communities (Connecting People Intervention [53]), increases their access to social capital and perceived social inclusion when implemented with high fidelity [54]. Increases in social network size may be attributable to service users being linked to community resources.

Interventions with an individual's friends stem from efficacious family interventions, but are considerably less developed. A narrative review [55] found no published evaluations of professionals meeting with the friends of a person with psychosis. However, the review authors presented a case study in which a mental health professional met with a person with psychosis and his friend to talk about his symptoms and undertake some relapse planning. This intervention helped him to regain contact with his wider friendship network and to find a job. This practice is common in mental health social work, but is not widely documented or evidenced.

The Open Dialogue Approach, which originated in Western Lapland, Finland, and now being trialled in the UK, also brings mental health professionals into contact with an individual's wider social network [56]. Mental health professionals meet with an individual's family, friends and wider network in regular treatment meetings to support people through an episode of psychosis. The
Open Dialogue Approach had positive outcomes in Finland where most young people experiencing their first episode of psychosis return to college or employment: $84 \%$ in the first two years [57], 86\% in the first five years [58]. Although social network outcomes are not measured, it is expected that an early return to college or employment would support maintenance or growth in social networks.

\section{Group-based community activities}

Community-based activities which develop skills and increase confidence also appear to support the development of relationships within and beyond groups. Horticulture and arts-based projects appear the most common form of activities. For example, group gardening in an urban farm increased the self-reported social activities of about a third of people with severe depression participating in one study [59]. Similarly, an ecotherapy intervention in an urban public space, whereby groups of people with severe and enduring mental health problems engaged in environmental conservation, resulted in stronger relationships within the group and more diverse connections beyond it [60]. In addition, participants in arts projects for people with mental health problems reported higher levels of social inclusion over time and stronger mutuality within groups [61, 62].

\section{Employment interventions}

Social network size and resourcefulness are correlated with employment status [63]. Therefore, interventions which help unemployed people find work are also likely to positively impact on their social networks. The approach with perhaps the strongest evidence base is 'supported employment', which involves matching people with enduring mental health problems to competitive jobs without extensive preparation. Supported employment seems to significantly increase levels of any employment obtained during the course of trials, but social network outcomes are rarely evaluated [64]. However, qualitative interviews evaluating outcomes of a project employing mental health service users as trainers, researchers or service providers found self-reported improvements in social life, social contacts and networks, though difficulties remained in maintaining close relationships $[65,66]$. This approach is not dissimilar to recovery colleges which employ mental health service users as course leaders, though evidence of their social network outcomes is currently lacking [67].

There is some limited evidence that participation in social enterprises produces mental health gains [68]. They appear able to build social capital among marginalised groups in society [69], though evaluations of social 
network outcomes for people with mental health problems are lacking.

\section{Peer support interventions}

Peer support interventions often focus on enhancing relationships among people with mental health problems rather than engaging with the wider community. Their focus on building stronger ties with people of shared identity and experiences may restrict opportunities to enhance connections with different social groups. A trial of peer support groups minimally facilitated by a psychiatric nurse [70] found that attendance at the groups improved peer contact, but did not have a similar impact on relationships beyond mental health services.

Similarly, a trial of adding peer support to intensive case management did not find significant differences across intervention conditions (treatment as usual, consumerassisted, and non-consumer-assisted case management) [71]. Instead, improvements were attributed to the robustness of the asset-based approach underlying all three interventions. Although the three programmes had distinct patterns of services (e.g. peers uniquely focused on socialisation, support and the use of peer-organised activities), participants listed professional staff as members of their network at the same rate as they claimed peers as members.

Evidence of the effectiveness of peer support interventions in general is limited. Many of the 18 trials included in a systematic review of peer support interventions [72] were at high risk of bias and did not include social network outcomes.

\section{Discussion}

A wide range of approaches are used to help improve the social participation of people with mental health problems, though evidence of their effectiveness is minimal. This review has included interventions delivered by mental health services in diverse service settings across the world. For example, in Italy, mental health professionals actively engaging people with a diagnosis of schizophrenia and small networks with activities and opportunities in their local communities [52] were found to statistically significantly improve social network size, which was sustained after two years. In Finland, the Open Dialog approach improved outcomes for young people experiencing firstepisode schizophrenia over a two-year period [56]. Some interventions included in this review were not delivered by mental health services [e.g. environmental volunteering, 60], but evidence of their effectiveness was more limited.

Using a similar model to supported employment, whereby people are supported to find jobs and keep them, supported community engagement directly exposes people to new social connections through mainstream opportunities within communities. This requires people to be sufficiently able and confident to engage in activities and networks accessed by the general population. It similarly requires people within communities to accept people with stigmatised identities and occasional behavioural challenges into their groups, activities and networks. This can be a significant challenge in some local areas, though there is evidence that national anti-stigma campaigns can help to improve attitudes towards mental health problems [73].

Supported community engagement interventions require mental health services to develop stronger connections with local community networks and activities. Mental health professionals need to be provided with the time and flexibility to develop local relationships and increase their knowledge about community engagement opportunities. The Connecting People Intervention model improves individual outcomes only when mental health professionals and the teams in which they work share ownership of their community connections so that its success is not reliant on the knowledge and connections of one or two workers, who may leave the service at any time [53, 54].

Supported community engagement interventions have the potential to increase the number of 'weak ties' within networks. 'Weak ties' have been defined by social network scholars as connections with more diverse people which increase the potential flow of information about jobs and other opportunities [63, 74]. 'Weak ties' enable people to get on and get ahead with their lives and should, arguably, be the target of social participation interventions. An increase in social network size should not be viewed as an end in itself, but the means to support people to achieve other recovery goals. To achieve this, mental health services may be able to connect with schemes in primary care such as social prescribing $[25,75]$ or to utilise web-based network tools [76] which help to connect people to local activities, groups and opportunities according to individuals' interests.

Group interventions help people to build supportive, trusting relationships, which are necessary prerequisites for social networks to develop. Similarly, peer support interventions appear to provide a supportive context for social engagement. However, they appear limited in supporting people to build social networks unless they actively and purposively engage people in community activities alongside the general population.

This is not a full systematic or scoping review, and some promising interventions may have been omitted due to them not being in the public domain or being missed by our search strategy. Further, it is beyond the scope of this review to discuss social media and other online tools which people use to connect with others, though we recognise 
that they can also facilitate social connections. We have not appraised the quality of the studies described here and our conclusions must therefore be accepted as tentative.

The evidence informing this review is limited as, with other social interventions in mental health services, social participation interventions are under-evaluated. There are neither Cochrane Reviews nor meta-analyses of outcome data; we have identified only two other systematic reviews in this field. Evaluations of social participation interventions are frequently pragmatic - as evidenced by the diversity of methods used by studies included in this reviewand randomised controlled trials are rare. However, trials are not always possible or desirable and cannot answer questions about the experience of social interventions by service users and workers, for example, which can impact on outcomes and their subsequent implementation by mental health services.

Studies included in this review used a variety of subjective and objective outcome measures, making it difficult to assess the efficacy of different approaches. In addition, social interventions such as peer support or employment interventions, which have been more widely evaluated [e.g. 72, 77], may increase social participation, but we have limited evidence of this as they are rarely evaluated using social network outcome measures.

The technical language of 'interventions' used in this review may appear to suggest that a social network 'fix' was being applied to people's lives. This is a consequence of using a shorthand term for complex and subtle human interactions, whereas many people's experience of recovery is that networks grow naturally through increased social participation. However, this review should be read as a summary of the current state of the literature on approaches to support people with mental health problems to engage in new social encounters.

This review highlights the need for additional research using experimental designs, sufficient sample sizes and longer follow-up periods (more than twelve months) to enable us to make firm recommendations for mental health policy or practice. Our knowledge in this field could also be enhanced by the inclusion of social network outcome measures in trials of other social interventions, such as supported employment or Open Dialogue. However, the limited evidence we have reviewed supports a move towards a more equal 'patient-clinician' partnership and a shared approach which accounts for local contexts and cultures to engage people more fully in the communities in which they live $[53,78]$.

\section{Compliance with ethical standards}

Conflict of interest On behalf of all authors, the corresponding author states that there is no conflict of interest.
Open Access This article is distributed under the terms of the Creative Commons Attribution 4.0 International License (http:// creativecommons.org/licenses/by/4.0/), which permits unrestricted use, distribution, and reproduction in any medium, provided you give appropriate credit to the original author(s) and the source, provide a link to the Creative Commons license, and indicate if changes were made.

\section{References}

1. Cohen S (2004) Social relationships and health. Am Psychol 59(8):676-684. doi:10.1037/0003-066x.59.8.676

2. Uchino BN (2006) Social support and health: a review of physiological processes potentially underlying links to disease outcomes. J Behav Med 29(4):377-387. doi:10.1007/ s10865-006-9056-5

3. Buchanan J (1995) Social support and schizophrenia: a review of the literature. Arch Psychiatr Nurs 9(2):68-76

4. Shor E, Roelfs DJ, Yogev T (2013) The strength of family ties: a meta-analysis and meta-regression of self-reported social support and mortality. Soc Netw 35(4):626-638. doi:10.1016/j. socnet.2013.08.004

5. Valtorta NK, Kanaan M, Gilbody S, Ronzi S, Hanratty B (2016) Loneliness and social isolation as risk factors for coronary heart disease and stroke: systematic review and meta-analysis of longitudinal observational studies. Heart 102(13):1009-1016. doi:10.1136/heartjnl-2015-308790

6. Holt-Lunstad J, Smith TB, Baker M, Harris T, Stephenson D (2015) Loneliness and social isolation as risk factors for mortality: a meta-analytic review. Perspect Psychol Sci 10(2):227-237. doi:10.1177/1745691614568352

7. Walsh E, Leese M, Taylor P, Johnston I, Burns T, Creed F, Higgit A, Murray R (2002) Psychosis in high-security and general psychiatric services. Report from the UK700 and Special Hospitals' Treatment Resistant Schizophrenia groups. Br J Psychiatry 180 (4):351-357. doi:10.1192/bjp.180.4.351

8. Anderson K, Laxhman N, Priebe S (2015) Can mental health interventions change social networks? A systematic review. BMC Psychiatry 15:297. doi:10.1186/s12888-015-0684-6

9. Killaspy H, White S, Lalvani N, Berg R, Thachil A, Kallumpuram S, Nasiruddin O, Wright C, Mezey G (2014) The impact of psychosis on social inclusion and associated factors. Int J Soc Psychiatry 60(2):148-154. doi:10.1177/0020764012471918

10. Thornicroft G, Strathdee G, Phelan M, Holloway F, Wykes T, Dunn G, McCrone P, Leese M, Johnson S, Szmukler G (1998) Rationale and design. PRiSM psychosis study I. Br J Psychiatry 173(5):363-370

11. Harvey CA, Pantelis C, Taylor J, McCabe PJ, Lefevre K, Campbell PG, Hirsch SR (1996) The Camden schizophrenia surveys II. High prevalence of schizophrenia in an inner London borough and its relationship to socio-demographic factors. Br J Psychiatry 168(4):418-426

12. Almquist YB, Landstedt E, Hammarström A (2017) Associations between social support and depressive symptoms: social causation or social selection-or both? Eur J Public Health 27(1):84-89. doi:10.1093/eurpub/ckw120

13. Stilo SA, Di Forti M, Mondelli V, Falcone AM, Russo M, O'Connor J, Palmer E, Paparelli A, Kolliakou A, Sirianni M, Taylor H, Handley R, Dazzan P, Pariante C, Marques TR, Zoccali R, David A, Murray RM, Morgan C (2013) Social disadvantage: cause or consequence of impending psychosis? Schizophr Bull 39(6):1288-1295. doi:10.1093/schbul/sbs112

14. Kawachi I, Berkman LF (2001) Social ties and mental health. J Urban Health 78(3):458-467 
15. Marroquín B, Nolen-Hoeksema S (2015) Emotion regulation and depressive symptoms: close relationships as social context and influence. J Pers Soc Psychol 109(5):836-855. doi: $10.1037 / \mathrm{pspi0000034}$

16. Becker T, Thornicroft G, Leese M, McCrone P, Johnson S, Albert M, Turner D (1997) Social networks and service use among representative cases of psychosis in south London. Br J Psychiatry 171:15-19

17. Harvey CA, Jeffreys SE, McNaught AS, Blizard RA, King MB (2007) The Camden schizophrenia surveys III: five-year outcome of a sample of individuals from a prevalence survey and the importance of social relationships. Int J Soc Psychiatry 53(4):340-356. doi:10.1177/0020764006074529

18. Choenarom C, Williams RA, Hagerty BM (2005) The role of sense of belonging and social support on stress and depression in individuals with depression. Arch Psychiatr Nurs 19(1):1829. doi:10.1016/j.apnu.2004.11.003

19. De Silva MJ, McKenzie K, Harpham T, Huttly SRA (2005) Social capital and mental illness: a systematic review. J Epidemiol Community Health 59(8):619-627

20. Pinto RM (2006) Using social network interventions to improve mentally ill clients' well-being. Clin Soc Work J 34(1):83-100. doi:10.1007/s10615-005-0005-5

21. Haber MG, Cohen JL, Lucas T, Baltes BB (2007) The relationship between self-reported received and perceived social support: a meta-analytic review. Am J Community Psychol 39(10):133-144

22. Davidson L, Harding C, Spaniol L (2005) Recovery from severe mental illnesses: research evidence and Implications for practice. Center for psychiatric rehabilitation. Boston University, Boston

23. Snethen G, McCormick BP, Van Puymbroeck M (2012) Community involvement, planning and coping skills: pilot outcomes of a recreational-therapy intervention for adults with schizophrenia. Disabil Rehabil 34(18):1575-1584. doi:10.3109/09638288.2 011.650315

24. Newlin M, Morris D, Howarth S, Webber M (2015) Social participation interventions for adults with mental health problems: a review and narrative synthesis. Soc Work Res 39(3):167-180

25. Mossabir R, Morris R, Kennedy A, Blickem C, Rogers A (2015) A scoping review to understand the effectiveness of linking schemes from healthcare providers to community resources to improve the health and well-being of people with longterm conditions. Health Soc Care Community 23(5):467-484. doi:10.1111/hsc.12176

26. Webber M (2005) Social capital and mental health. In: Tew J (ed) Social perspectives in mental health. Developing social models to understand and work with mental distress. Jessica Kingsley Publishers, London, pp 90-111

27. Webber M, Huxley P, Harris T (2011) Social capital and the course of depression: six-month prospective cohort study. J Affect Disord 129(1-2):149-157

28. Popay J, Roberts H, Sowden A, Petticrew M, Arai L, Britten N (2006) Guidance on the conduct of narrative synthesis in systematic reviews: final report. ESRC Methods Programme, Manchester

29. Huprich SK, Clancy C, Bornstein RF, Nelson-Gray RO (2004) Do dependency and social skills combine to predict depression? Linking two diatheses in mood disorders research. Individ Differ Res 2(1):2-16

30. Glynn SM, Marder SR, Liberman RP, Blair K, Wirshing WC, Wirshing DA, Ross D, Mintz J (2002) Supplementing clinicbased skills training with manual-based community support sessions: effects on social adjustment of patients with schizophrenia. Am J Psychiatry 159(5):829-837. doi:10.1176/appi. ajp.159.5.829
31. National Institute for Health and Care Excellence (2014) Psychosis and schizophrenia in adults: treatment and management. NICE clinical guideline 178. National Institute for Health and Care Excellence, London

32. Almerie MQ, Al Marhi MO, Jawoosh M, Alsabbagh M, Matar HE, Maayan N, Bergman H (2015) Social skills programmes for schizophrenia. Cochrane Database Syst Rev 2. doi:10.1002/14651858.cd009006

33. Koekkoek B, van Meijel B, Schene A, Hutschemaekers G (2010) Development of an intervention program to increase effective behaviours by patients and clinicians in psychiatric services: intervention Mapping study. BMC Health Serv Res 10(1):293. doi:10.1186/1472-6963-10-293

34. Koekkoek B, van Meijel B, Schene A, Smit A, Kaasenbrood A, Hutschemaekers G (2012) Interpersonal community psychiatric treatment for non-psychotic chronic patients and nurses in outpatient mental health care: a controlled pilot study on feasibility and effects. Int J Nurs Stud 49(5):549-559. doi:10.1016/j. ijnurstu.2011.11.003

35. Knott G, Bannigan K (2013) A Critical Review of the approved mental health professional role and occupational therapy. Br J Occup Ther 76(3):118-126. doi:10.4276/0308022 $13 \times 13627524435108$

36. Gammonley D, Luken K (2001) Peer education and advocacy through recreation and leadership. Psychiatr Rehabil J 25(2):170-178. doi:10.1037/h0095028

37. Geurtsen GJ, Martina JD, Van Heugten CM, Geurts ACH (2008) A prospective study to evaluate a new residential community reintegration programme for severe chronic brain injury: the Brain Integration Programme. Brain Inj 22(7-8):545-554. doi:10.1080/02699050802132479

38. Haslam C, Cruwys T, Haslam S, Dingle G, Chang MX-L (2016) GROUPS 4 HEALTH: evidence that a social-identity intervention that builds and strengthens social group membership improves mental health. J Affect Disord 194:188-195. doi:10.1016/j.jad.2016.01.010

39. Tajfel H, Turner J (1979) An integrative theory of intergroup conflict. In: Austin WG, Worchel S (eds) The Social Psychology of intergroup relations. Brooks/Cole, Monterey, CA, pp 33-47

40. Turner JC, Hogg MA, Oakes PJ, Reicher SD, Wetherell MS (1987) Rediscovering the Social group: a self-categorization theory. Blackwell, New York

41. Iyer A, Jetten J, Tsivrikos D (2008) Torn between identities: predictors of adjustment to identity change. In: Sani F (ed) Self-continuity: individual and collective perspectives. Psychology Press, New York, pp 187-197

42. Roberts DL, Penn DL, Combs DR (2016) Social cognition and interaction training (SCIT): treatment manual. Oxford University Press, New York

43. Bartholomeusz CF, Allott K, Killackey E, Liu P, Wood SJ, Thompson A (2013) Social cognition training as an intervention for improving functional outcome in first-episode psychosis: a feasibility study. Early Interv Psychiatry 7(4):421-426. doi:10.1111/eip.12036

44. Chan RC, Gao XJ, Li XY, Li HH, Cui JF, Deng YY, Wang Y (2010) The social cognition and interaction training (SCIT): an extension to individuals with schizotypal personality features. Psychiatry Res 178(1):208-210. doi:10.1016/j. psychres.2010.03.017

45. Roberts DL, Combs DR, Willoughby M, Mintz J, Gibson C, Rupp B, Penn DL (2014) A randomized, controlled trial of social cognition and interaction training (SCIT) for outpatients with schizophrenia spectrum disorders. Br J Clin Psychol 53(3):281298. doi:10.1111/bjc. 12044

46. Hasson-Ohayon I, Mashiach-Eizenberg M, Avidan M, Roberts DL, Roe D (2014) Social cognition and interaction 
training: preliminary results of an RCT in a community setting in Israel. Psychiatric services (Washington, DC) 65 (4):555-558. doi:10.1176/appi.ps.201300146

47. Wang Y, Roberts DL, Xu B, Cao R, Yan M, Jiang Q (2013) Social cognition and interaction training for patients with stable schizophrenia in Chinese community settings. Psychiatry Res 210(3):751-755. doi:10.1016/j.psychres.2013.08.038

48. Mead N, Lester H, Chew-Graham C, Gask L, Bower P (2010) Effects of befriending on depressive symptoms and distress: systematic review and meta-analysis. Br J Psychiatry 196(2):96101. doi:10.1192/bjp.bp.109.064089

49. Sheridan AJ, Drennan J, Coughlan B, O'Keeffe D, Frazer K, Kemple M, Alexander D, Howlin F, Fahy A, Kow V, O'Callaghan E (2015) Improving social functioning and reducing social isolation and loneliness among people with enduring mental illness: Report of a randomised controlled trial of supported socialisation. Int J Soc Psychiatry 61(3):241-250. doi:10.1177/0020764014540150

50. Barbato A, Agnetti G, D’Avanzo B, Frova M, Guerrini A, Tettamanti M (2007) Outcome of community-based rehabilitation program for people with mental illness who are considered difficult to treat. J Rehabil Res Dev 44(6):775-783

51. Middelboe T (1997) Prospective study of clinical and social outcome of stay in small group homes for people with mental illness. Br J Psychiatry 171(3):251-255. doi:10.1192/bjp.171.3.251

52. Terzian E, Tognoni G, Bracco R, De Ruggieri E, Ficociello RA, Mezzina R, Pillo G (2013) Social network intervention in patients with schizophrenia and marked social withdrawal: a randomized controlled study. Can J Psychiatry 58(11):622-631

53. Webber M, Reidy H, Ansari D, Stevens M, Morris D (2016) Developing and modelling complex social interventions: introducing the connecting people intervention. Res Soc Work Pract 26(1):14-19

54. Webber M, Morris D, Howarth S, Newlin M, Treacy S, McCrone P Effect of the Connecting People Intervention on social capital: a pilot study. Res Soc Work Pract (under review)

55. Harrop C, Ellett L, Brand R, Lobban F (2015) Friends interventions in psychosis: a narrative review and call to action. Early Interv Psychiatry 9(4):269-278. doi:10.1111/eip.12172

56. Seikkula J, Olson ME (2003) The open dialogue approach to acute psychosis: its poetics and micropolitics. Fam Process 42(3):403-418. doi:10.1111/j.1545-5300.2003.00403.x

57. Seikkula J, Alakare B, Aaltonen J (2011) The comprehensive open-dialogue approach in Western Lapland: II. Long-term stability of acute psychosis outcomes in advanced community care. Psychosis Psychol Soc Integr Approaches 3(3):192-204. doi:10. 1080/17522439.2011.595819

58. Seikkula J, Aaltonen J, Alakare B, Haarakangas K, Keränen J, Lehtinen K (2006) Five-year experience of first-episode nonaffective psychosis in open-dialogue approach: treatment principles, follow-up outcomes, and two case studies. Psychother Res 16(2):214-228. doi:10.1080/10503300500268490

59. Gonzalez MT, Hartig T, Patil GG, Martinsen EW, Kirkevold M (2011) A prospective study of group cohesiveness in therapeutic horticulture for clinical depression. Int J Ment Health Nurs 20(2):119-129. doi:10.1111/j.1447-0349.2010.00689.x

60. O'Brien L, Burls A, Townsend M, Ebden M (2011) Volunteering in nature as a way of enabling people to reintegrate into society. Perspect Public Health 131(2):71-81. doi:10.1177/1757913910384048

61. Spandler H, Secker J, Kent L, Hacking S, Shenton J (2007) Catching life: the contribution of arts initiatives to recovery approaches in mental health. J Psychiatr Ment Health Nurs 14(8):791-799. doi:10.1111/j.1365-2850.2007.01174.x

62. Hacking S, Secker J, Spandler H, Kent L, Shenton J (2008) Evaluating the impact of participatory art projects for people with mental health needs. Health Soc Care Community 16(6):638-648
63. Lin N (2001) Social Capital. A theory of social structure and action. Structural analysis in the social sciences. Cambridge University Press, Cambridge

64. Kinoshita Y, Furukawa TA, Kinoshita K, Honyashiki M, Omori IM, Marshall M, Bond GR, Huxley P, Amano N, Kingdon D (2013) Supported employment for adults with severe mental illness. Cochrane Database Syst Rev 9. doi:10.1002/14651858. CD14008297.pub14651852

65. Nieminen I, Ramon S, Dawson I, Flores P, Leahy E, Pedersen ML, Kaunonen M (2012) Experiences of social inclusion and employment of mental health service users in a European union project. Int J Ment Health 41(4):3-23. doi:10.2753/IMH0020-7411410401

66. Ramon S, Griffiths CA, Nieminen I, Pedersen M, Dawson I (2011) Towards social inclusion through lifelong learning in mental health: analysis of change in the lives of the Emilia project service users. Int $\mathbf{J}$ Soc Psychiatry 57(3):211-223. doi:10.1177/0020764009354943

67. Meddings S, McGregor J, Roeg W, Shepherd G (2015) Recovery colleges: quality and outcomes. Ment Health Soc Incl 19 (4):212221. doi:10.1108/MHSI-08-2015-0035

68. Roy MJ, Donaldson C, Baker R, Kerr S (2014) The potential of social enterprise to enhance health and well-being: a model and systematic review. Soc Sci Med 123:182-193. doi:10.1016/j. socscimed.2014.07.031

69. Ho AP-y, Chan K-t (2010) The social impact of work-integration social enterprise in Hong Kong. Int Soc Work 53(1):33-45. doi: $10.1177 / 0020872809348950$

70. Castelein S, Bruggeman R, van Busschbach JT, van der Gaag M, Stant AD, Knegtering H, Wiersma D (2008) The effectiveness of peer support groups in psychosis: a randomized controlled trial. Acta Psychiatr Scand 118(1):64-72

71. James J, Rivera PD, Ann M, Sullivan MD, Stavros Valenti PD S (2007) Adding consumer-providers to intensive case management: does it improve outcome? Psychiatr Serv 58(6):802-809. doi:10.1176/ps.2007.58.6.802

72. Lloyd-Evans B, Mayo-Wilson E, Harrison B, Istead H, Brown E, Pilling S, Johnson S, Kendall T (2014) A systematic review and meta-analysis of randomised controlled trials of peer support for people with severe mental illness. BMC Psychiatry 14(1):39. doi:10.1186/1471-244x-14-39

73. Evans-Lacko S, Corker E, Williams P, Henderson C, Thornicroft G (2014) Effect of the time to change anti-stigma campaign on trends in mental-illness-related public stigma among the English population in 2003-13: an analysis of survey data. Lancet Psychiatry 1(2):121-128. doi:10.1016/S2215-0366(14)70243-3

74. Granovetter MS (1973) The strength of weak ties. Am J Sociol 78(6): 1360-1380

75. Whitelaw S, Thirlwall C, Morrison A, Osborne J, Tattum L, Walker S (2017) Developing and implementing a social prescribing initiative in primary care: insights into the possibility of normalisation and sustainability from a UK case study. Prim Health Care Res Dev 18(2):112-121. doi:10.1017/S1463423616000219

76. Kennedy A, Vassilev I, James E, Rogers A (2016) Implementing a social network intervention designed to enhance and diversify support for people with long-term conditions. A qualitative study. Implement Sci 11(1):27. doi:10.1186/s13012-016-0384-8

77. Marshall T, Goldberg RW, Braude L, Dougherty RH, Daniels AS, Ghose SS, George P, Delphin-Rittmon ME (2014) Supported employment: assessing the evidence. Psychiatr Serv 65(1):16-23. doi:10.1176/appi.ps.201300262

78. Jacob KS (2014) DSM-5 and culture: the need to move towards a shared model of care within a more equal patient-physician partnership. Asian J Psychiatr 7(1):89-91. doi:10.1016/j.ajp.2013.11.012 